\title{
Sustainable Development Goals (SDGs):
}

\section{Far from Achievement for Sub-Saharan Africa}

\begin{abstract}
Sustainable development goals (SDGs) are a global agenda consisting of 17 goals which are to be achieved in 2030 by all member states. SDGs are more holistic goals i.e. these goals are closely interrelated and they affect the progress of one another. Sub-Saharan Africa countries are, once more lagging behind in the implementations of SDGs despite the efforts by governments, non-government organisations and international agencies. Rwanda, South Africa and Zambia where the three Sub-Saharan Africa countries on which the study focused. The three countries in this study were chosen on the basis that they cater to the general overview of African countries performance on SDGs. To conduct this study, a desk research method was adopted and secondary data was utilised. An in-depth analysis was done on the on three subs Saharan African countries i.e. Rwanda, South Africa, Zambia. Those goals where serious attention is needed are goals 1-9, 16 and 17. Most Sub-Saharan African countries performed better on goals 11, 12 and 15. It was concluded that the achievement of Sustainable development goals remains a mere dream for Sub Saharan Africa unless serious interventions are made.
\end{abstract}

Keywords: Sustainable development goals (SDGs); Rwanda; South Africa; Zambia; subSaharan Africa 


\section{INTRODUCTION}

Sustainable Development Goals are a global agenda consisting of 17 goals which are to be achieved in 2030 by all member states (UNECFA, 2015). Sustainable development goals succeeded the Millennium Development Goals (MDGs) that were eight international development goals set for 2015. Critics of MDGs points out that goals lacked analysis and justification behind the chosen objectives and the lack of measurement for some goals made their implementation challenging. Further, MDGs had uneven progress between member countries as some countries achieved all the goals i.e. Nordic countries, while others did not make significant progress i.e. Sub-Saharan African countries. Therefore, more holistic goals were introduced, these goals are closely interrelated and they affect the progress of one another.

According to (Sachs, Schmidt, durand, \& Teksoz, 2017) Sub-Saharan Africa countries are, once more lagging behind in the implementations of SDGs despite the efforts by governments, non-government organisations and international agencies. Sub-Saharan Africa continues to perform badly even top-ranked countries like South Africa continue facing significant challenges. The three countries in this study were chosen on the basis that they cater to the general overview of African countries performance on SDGs.

\section{Materials and methods}

To conduct this study, a desk research method was adopted and secondary data was utilised. The sustainable development report for 2019 by UN, Sustainable index report and dashboard report 2017, the literature on development in Zambia, Rwanda and South Africa were reviewed. An in-depth analysis was done on the on three subs Saharan African countries i.e. Rwanda, South Africa, Zambia as these countries represents the general overview for subAfrican countries. Bertelsmann Stiftung and Sustainable Development Solutions Network have attempted to put forward the performance of all UN member countries on sustainable development for the year 2019. The report was measured across 162 indicators to measure all the seventeen SDGs. For Rwanda, South Africa and Zambia 85 indicators on all the seventeen SDGs and an analysis was done on the overall SDGs Index in this study. A classification of SDGs as: 


\begin{tabular}{|l|l|}
\hline Scores & Classification \\
\hline $0-49$ & Major Challenges \\
\hline $50-69$ & Significant challenges remains \\
\hline $70-99$ & Challenges remains \\
\hline 100 & Achieved goals \\
\hline
\end{tabular}

\section{Looking at the SDGS scores.}

This section looks at the overall performance of Rwanda, South Africa and Zambia in terms of SDGs scores.

Table 1 shows a detailed performance of three selected countries in Africa on SDGs performances i.e. Rwanda, South Africa and Zambia. The measurements are done using SDGs index score (percent). The first category is denoted as goals with major challenges (049) SDGs index score. In these three nations, most goals remain with major challenges such that Rwanda has five SDGs viz. SDG1, SDG2,SDG7,SDG9 and SDG10. which have major challenges, South Africa has four SDGs viz. SDG1,SDG3,SDG9 and SDG10 that face major challenges while Zambia has seven SDGs viz. SDG1, SDG2, SDG3, SDG7,SDG9,SDG10 and SDG16 that are facing major challenges. All the countries face major challenges concerning SDG1 i.e. ending poverty in all its form, SGG9 i.e. industry, innovation and infrastructure and SDG10 i.e. reduce inequalities.

Further classification is for the those goals whose index scores is between (50-65) and these goals are classified as significant challenges remains. Six of Rwanda's SDGs viz. SDG2,SDG3,SDG4,SDG6,SDG11 and SDG17 remains in this category. Five SDGs face significant challenges in South Africa viz. SDG2,SDG8,SDG14,SDG15 and SDG16. While four of Zambia's SDGs viz. SDG4,SDG5, SDG6 and SDG11 are in this category.

Goals with index score ( 65-99) are classified as challenges remains. In this category Rwanda has six SDGs viz. SDG5,SDG8,SDG12,SDG13,SDG15 and SDG17. Most of South Africa's SDGs remains in this category, with eight of its SDGs belonging to this category viz. 
SDG4, SDG5,SDG6,SDG7,SDG11,SDG12,SDG13 and SDG17. Zambia has four of its SDGs in this category viz. SDG12,SDG13 and SDG15.

The category for achieved goals has not been attained by any country. The overall SDGs s ores for all the countries have significant challenges. Rwanda and Zambia has no data on SDG14 i.e. Life below water.

Table 1. Performance of countries by SDG for 2019

\begin{tabular}{|l|l|l|l|}
\hline \multirow{2}{*}{ SDGs } & \multicolumn{3}{l}{ Scores of countries } \\
\cline { 2 - 4 } & Rwanda & South Africa & Zambia \\
\hline SDG 1:No Poverty & 17.1 & 49.9 & 13.5 \\
\hline SDG 2: Zero Hunger & 51.7 & 52.5 & 42.9 \\
\hline SDG 3: Good Health \& Well-being & 60.0 & 48.7 & 46.5 \\
\hline SDG 4: Quality Education & 60.9 & 78.1 & 62.7 \\
\hline SDG 5: Gender Equality & 80.5 & 80.1 & 63.6 \\
\hline SDG 6: Clean Water \& Sanitation & 56.2 & 67.0 & 52.6 \\
\hline SDG 7: Affordable \& Clean Energy & 11.1 & 79.0 & 43.5 \\
\hline SDG 8: Decent Work \& Economic Growth & 69.8 & 61.2 & 67.2 \\
\hline SDG 9: Industry, Innovation, \& Infrastructure & 15.7 & 45.0 & 16.6 \\
\hline SDG 10: Reduced Inequality & 27.3 & 0.0 & 16.6 \\
\hline SDG 11: Sustainable Cities \& Communities & 58.6 & 77.9 & 63.4 \\
\hline SDG 12: Sustainable Consumption \& Production & 95.8 & 68.8 & 89.7 \\
\hline SDG 13: Climate Action & 98.6 & 87.0 & 98.4 \\
\hline SDG 14: Life Below Water & Na & 56.5 & Na \\
\hline SDG 15: Life on Land & 66.5 & 59.1 & 70.3 \\
\hline SDG 16: Peace, Justice \& Strong Institutions & 70.9 & 54.9 & 45 \\
\hline SDG 17: Global Partnership & 57.1 & 79.5 & 46.9 \\
\hline SDG index score & $\mathbf{5 6}$ & $\mathbf{6 1 . 5}$ & 52.6 \\
\hline
\end{tabular}

Source: Bertelsmann Stiftung Sustainable development report 2019.

Note: In this study the index scores are classified as; Achieved goals(100), Challenges remains(70-99), Significant challenges remains (50-69), Major challenges ( 0-49).

\section{Goals which major challenges remains}

Considering all the indicators analysed it is now important to note that Rwanda has four goals where major challenges exists, viz. SDG1, SDG7,SDG9 and SDG10. South Africa has four goals where major challenges exists viz. SDG1, SDG3, SDG9 and SDG10. Zambia on the other hand has 7 Goals facing major challenges viz. SDG2, SDG3, SDG7, SDG9, SDG10 and SDG16. Figure 1. 
Figure 1. Goals which major challenges remains



Note: Major challenges are the goals in which the index score of the concerned country is between ( 0-49).

\section{What the countries doing?}

In addition to the SDGs 2030 agenda, African countries have committed to implement their own national agenda. The 2030 global agenda acknowledges the significance of these national agendas and considers it as an integral part of it .Several countries are already taking steps to translate the ambitions articulated in the 2030 Agenda into tangible outcomes for their people; they are beginning with integrating the SDGs into their national visions and plans. Therefore it important to look at how these countries i.e. Rwanda, South Africa and Zambia are doing to ensure the progress.

\subsection{Rwanda}

Rwanda experienced genocide 25 years ago as a result, the country was left behind on all social-economic spheres. Since early 2000s Rwanda has registered consistency in socialeconomic growth. Rwanda which had most impoverished people in 1990s is now one of the fastest-growing economies in sub-Saharan Africa. For achieving SDGs Rwanda has integrated them into its national development agenda through the draft vision 2050, the national strategy for transformation (NST1, 2017-2024). The key components of the NST1 are; (i) Human capital development (ii) inclusive development growth (iii) environment and climate change (iv) Good governance and access to justice (v) strengthening the means of implementation, global partnership and data for SDGs (United-nations, 2019) 
Studies done in Africa reveals that the international measurement of poverty in dollar does not represent poverty as a multidimensional phenomenon like it is. The materials and wealth that constitutes the welfare and well being of people in Africa especially in rural areas cannot be quantified into international poverty standards which is measured $\$ 1.9$ per day. Therefore what is referred to as standard international poverty line might contradict the official government reports. (Dawson, 2018)

Rwanda rural population immensely depends on agriculture. Therefore the government has put in efforts to combat the climate change impacts. Climate change remains a challenge in this country whose major contributor to the economy is rain dependant agriculture. (GGGI, 2016)

Improvement is needed in the area of energy as a study by (UNEP, 2011) points out the energy sector in Rwanda have suffered chronic neglect due to minimal investments. This negatively impacts the vast majority of citizens who have to depend on Biomass for energy, mainly fuel from firewood and charcoal. The study points out that with population increase the energy sector will continue to dwindle.

With massive economic and national building comes the effect on public health. Rwanda is no exception in this scenario as inadequate and unsafe drinking water, poor drainage system; solid waste management and construction in inappropriate and hazardous areas are scaling up. However the national and local government are putting in adequate efforts to curb these challenges. (UNEP, 2011)

Rwanda strategy to achieving SDGs should be commended as the country strives in domestication of the goals. Any meaningful development should be ground up oriented and Rwanda is striving in doing that. (Theogene, ferdinand, Leonidas, \& Josephine, 2018)

\subsection{South Africa}

2019 marked 25 years of since South Africa gained its independence. The country has improved the livelihood of its citizen since then by addressing issues of extreme poverty, school access through pro-poor taxes systems that supported the provisions of free basic services. South Africa has been on the front line in development of SDGs in the world, in the AU and SADC region. The commitment of South Africa towards implementations and achievements of SDGs can be seen through efforts like the national development plan (NDP) vision 2030 which acts as South Africa road map and guideline towards development. The 
NDP which was adopted in 2012 had to align itself with SDGs. The key components of the NDP are: (i) social protection (ii) Improving education, training and innovation (iii) promoting health, economy and employment (iv) an integrated and inclusive rural economy. (The Government of south-Africa, 2019) In addition, the government of South Africa has adopted several National frameworks for sustainable development. South Africa trends in high income inequality can be attributed to the fact that most countries with high per capita income also experiences higher income inequalities. Issues of lower life expectancy are hailed on the higher rates of HIV in the country. (UNECFA, 2015)

The South African government realises the importance of localising SDGs, as of 2015 the government of South Africa ensures that all stakeholders are included in SDGs implementations i.e. government collaborates with provincial, local governments, parliament, civil society academia and the private sector. Although these efforts are being taken, localisation of SDGs remains unorganised as few local governments actively engage in SDGs implementations (Sylvia, Carol, \& Natasha, 2019)

\subsection{Zambia}

Zambia 2030 vision devised in 2006 expressed the nation's aspiration on what they wanted to be achieved in 2030. In 2017 the first draft of $7^{\text {th }}$ national development plan for years 2017 to 2021 was introduced with the focus on (i) gender-responsive development (ii) democracy and good governance (iii) respect for human rights (iv) good traditions and family values (v) a positive attitude towards work (vii) peaceful coexistence (viii) private pubic partnerships. Even when efforts have been made towards SDGs achieving them will likely be difficult for Zambia. (Sichingabula, 2017) Clean water and sanitation continues to be a major challenge in Zambia, however in 2010 the country had improved the proportion of population with access to clean water. On one hand access to proper sanitation has improved though remains a challenge. On the other hand sanitation in the country had worsened from 26 percent in 1991 to 67.3 percent in 2010 especially in rural Zambia is the one which is affected badly. (Charles, Choolwe, Margrete, \& Silumbwe, 2017)

Efforts to domesticate SDGs are in place, however as a study by (Charles, Choolwe, Margrete, \& Silumbwe, 2017) reveals, that there is lack of clarity on prioritisation and inclusion of SDGs into local development agenda. The challenges of meeting some of SDGs targets are faced due to lack of resources. 
To implement Sustainable development capacity building is vital says (Jaiyesimi, 2016). However a quick perusal of data shows that capacity building in Zambia is not done extensively. Therefore it's high time that Zambia calls upon its skilled professionals to help in the implementing SDGs.

\section{CONCLUSIONS}

It was concluded that the achievement of Sustainable development goals remains a mere dream for Sub Saharan Africa unless serious interventions are made. Most Sub-Saharan African countries performed better on goals 11, 12 and 15. Those goals where serious attention is needed are goals 1-9, 16 and 17. Hunger can be eliminated when the productivity is improved; however, all the three nations show a very poor yield of cereals tonnes per hectare. The challenge which most sub-Saharan countries face is the high rates of HIV/Aids and lower rates of life expectancy. While global life expectancy in 2019 was at 72.6 years the average life expectancy for 61 years. Education and health should be a priority for governments. Unfortunately, Zambia and Rwanda spend less than 6\% of their GDP on health and education as a result low rates of students' complete lower secondary school, which affects literacy rates in the region.Some improvements have been made in the area of equality for example Rwanda has done better not only in the region but in the world. The country is among the first few nations in the world to have more than $50 \%$ of women in the national parliament. The country's women participation in the labour force was at $99.9 \%$ in 2019.Access to clean water and sanitation remains a challenge for sub-Saharan Africa with more than 50 per cent of the population has lacking access to clean in Rwanda and Zambia. Therefore interventions should be priority efforts like borehole sinking should be recommended. The following observations are made while perusing on the data: South Africa cases of murder are very high which makes people feel unsafe. The freedom of the press is not good in Rwanda and more children are involved in the labour force in Zambia.

\section{REFERENCES}


Charles, M., Choolwe, N. j., Margrete, N. M., \& Silumbwe, A. (2017). Assessing Zambia's Preparedeness to implement Sustainable Devlopment on Heath. African Center for Global and Social Transformation Zambia.

Dawson, N. M. (2018). Leaving no-one behind? Social inequalities and contrasting impacts in rural Rwanda . Development studies research, 1-14.

GGGI. (2016). Rwanda Country Planning Framework-Rwanda. Global Green Growth Institute.

Jaiyesimi, R. (2016). The challenges of Implementing the Sustainable Development Goals in Africa: The way forward. African journal of reproductive health, 13-18.

Sach, j., Schmid-traub, G., Kroll, C., Lafortune, G., \& G, F. (2019). Sustainable Development Report. New york: Bertelsmann Stiftung and Sustainable Development Solutions Network (SDSN).

Sachs, j., Schmidt-Traub:G, K., durand-declare, D., \& Teksoz, K. (2017). SDG index and dashboards report 2017-Metadata. Gutersloh and newyork: Bertelsmann Stiftung and Sustainable Development Solutions Network (SDSN).

Sichingabula, H. .. (2017, 07). ZAMBIA'S IMPLEMENTATION OF SUSTANAIBLE DEVELOPMENT GOALS. UNIVERSITY OF ZAMBIA.

Sylvia, C., Carol, W., \& Natasha, P. (2019). Localisation of the 2030 Agenda and its Sustainabe Development Goals in Cape Town. cape town.

The Government of south-Africa. (2019). Sustanaible develoment goals in south africa: Voluntary National review.

Theogene, R., ferdinand, N., Leonidas, B., \& Josephine, U. (2018). Achieveing the Sustainable Development Goals in Rwanda: The role of Adminstrative Data Inclusion. East Africa collabrative PhD Program in Economics and Management.

UNECFA. (2015). Sustainable development goals for Southern Africa subregion. Addis Ababa, Ethiopia: United nations Economic Commission for Africa.

UNEP. (2011). Rwanda from post conflict to Enviromrntally Sustainable Development. Nairobi Kenya: United Nations Environmnent Programme .

United-nations. (2019, MAY 20). high level political forum on sustanable develoment. Retrieved from SUSTAINABLE DEVELOMENT GOALS KNOWLEDGE PLATFORM: http:sustainabledevelopmentgoals.un.org/hlpf 